\title{
Existe uma Demanda de Transparência? Análise de comentários à Projetos de Lei
}

\author{
Roxana Lisette Quintanilla Portugal ${ }^{1}$, Priscila Engiel ${ }^{1,2}$, \\ Julio Cesar Sampaio do Prado Leite
}

' Departamento de Informática, PUC-Rio, Rio de Janeiro, Brasil

${ }^{2}$ Dpto. de Engenharia de Computação e Informação da Universidade de Trento, Itália

\{rportugal, pengiel, julio\}einf.puc-rio.br

\begin{abstract}
In 2014, Engiel et al. manually verified the demand for transparency on the Votenaweb site for the bills of the year 2013. In 2016, Engiel et al. used text mining in the existing bills at the site (5011) with the same goal. There were 131 bills rated as $10+$ voted and $10+$ transparent. Of the $10+$ transparent, this work extracted its comments to check if there was any tendency or demand for transparency. As a result, six bills have been identified for having comments that demand transparency. For those comments a qualitative analysis is presented.
\end{abstract}

Resumo. Em 2014, Engiel et al. verificaram manualmente a demanda por transparência no site Votenaweb para os projetos de lei no ano de 2013. Em 2016, Engiel et al. usaram técnicas de mineração, cobrindo os projetos de lei até aquela data (5011) com o mesmo objetivo. Foram encontrados 131 projetos de leis classificados nos $10+$ votados e 10+ transparentes. Dos $10+$ transparentes, esse trabalho minerou os comentários existentes no site para verificar o que a população estava falando e se existia alguma tendência ou demanda. Como resultado, 6 projetos de lei foram identificados por possuir comentários que demandam transparência. Uma análise qualitativa é apresentada sobre esses comentários.

Palavras-Chave: Transparência, Projetos de Lei, Mineração de Texto

\section{Introdução}

O estudo de transparência como umbilicalmente ligada a sociedades democráticas tem tido um forte interesse da comunidade de pesquisa: tanto o WTranS como a Global Conference on Transparency Research demonstram esse fato. No entanto, é importante saber de que maneira os cidadãos demonstram uma demanda por transparência.

Nesse artigo exploramos uma estratégia de entendimento da demanda através do sítio Votenaweb (http://www.votenaweb.com.br/), uma iniciativa que reúne projetos de lei. O Votenaweb disponibiliza o resumo de projetos de lei, e possibilita que a população avalie se concorda ou não, podendo comentar sobre esses. 
Os autores desse trabalho trabalham com as informações disponibilizadas nesse site como insumo para analise dessa demanda. Primeiramente, (Engiel et al., 2014) usaram uma análise manual, como melhoria (Engiel et al., 2016) propuseram o uso de mineração de textos, possibilitando cobrir todos os projetos de lei. Continuando as melhorias e análises, o presente trabalho propõe estender a mineração de textos para os comentários. Dessa maneira indo além do voto e procurando extrair dos comentários se eles são demandantes de transparência.

A abordagem proposta tem como objetivo estudar se há uma demanda crescente por transparência, tanto pelos políticos como pelos cidadãos. Ao transparecer o que o cidadão opina, a percepção da aprovação/negação de um projeto de lei melhora e também possibilita a identificação de outras demandas.

O trabalho está organizado da seguinte forma. Capitulo 2 apresenta as atividades realizadas sobre os comentários. Capítulo 3 detalha a análise dos comentários achados como relevantes pela mineração de textos. Capitulo 4 descreve brevemente trabalhos relacionados. Finalmente a conclusão que inclui os trabalhos futuros.

\section{Mineração dos comentários}

Para realizar a mineração dos textos dos comentários dos projetos de lei, se utilizou como ponto de partida o ranking dos 10 projetos de lei mais transparentes (Tabela 1). (Engiel et al., 2016). Para cada um dos projetos foi realizado um script automatizado (crawling) para a recuperação dos comentários, e foram classificados de acordo com a sua votação (sim, não, indeciso). Os comentários de cada projeto sem processamento estão publicados no repositório GitHub (https://git.io/v9wyJ [issues 14-16]), de forma a oferecer transparência e possibilitar futuras pesquisas.

A mineração dos comentários dos projetos de lei foi sistematizada em três atividades que permitem descobrir os comentários relacionados a transparência, essas atividades são descritas brevemente a seguir.

Tabela 1. 10+ transparentes (Engiel, 2016)

\begin{tabular}{|l|c|}
\hline \multicolumn{1}{|c|}{ Projeto de Lei } & $\begin{array}{c}\% \text { Voto } \\
\text { (sim) }\end{array}$ \\
\hline Determinará obrigações para a realização de audiências públicas. & $95 \%$ \\
\hline $\begin{array}{l}\text { Tornará obrigatória a divulgação, na internet, da folha de pagamento dos funcionários da Administração Pública Direta e } \\
\text { Indireta, incluindo adicionais, auxílios e gratificações }\end{array}$ & $94 \%$ \\
\hline Obrigará a OAB e os outros conselhos profissionais a se submeterem às regras da Lei de Acesso à Informação & $97 \%$ \\
\hline $\begin{array}{l}\text { Obrigará as universidades públicas e as unidades de pesquisa a criarem arquivos online, de acesso livre, para guardar toda a } \\
\text { produção científica dos estudantes, professores, pesquisadores e colaboradores. }\end{array}$ & $92 \%$ \\
\hline Modificará o sistema de arquivamento dos votos em urnas eletrônicas e os mecanismos de transparência dos votos. & $72 \%$ \\
\hline $\begin{array}{l}\text { Obrigará as empresas estatais federais a divulgarem, de 3 em 3 meses, as despesas realizadas com publicidade e patrocínio } \\
\text { no Diário Oficial da União e em jornais de circulação nacional, para aumentar a transparência dos gastos públicos. }\end{array}$ & $93 \%$ \\
\hline Regulamentará a licitação e a contratação de serviços de publicidade por parte da administração pública. & $86 \%$ \\
\hline Instituirá o programa de Unidades de Polícia Pacificadora (UPP's) em todo território nacional. & $61 \%$ \\
\hline $\begin{array}{l}\text { Excluirá da Presidência da República a Controladoria-Geral da União, modificará o Conselho de Governo, passará as } \\
\text { competências do Departamento de Saúde Indígena, para o Ministério da Saúde, entre outras mudanças no Poder Executivo. }\end{array}$ & $18 \%$ \\
\hline $\begin{array}{l}\text { Obrigará todos os senadores, deputados e vereadores a realizar audiências públicas mensal com o objetivo de prestar } \\
\text { informações sobre sua atuação parlamentar. }\end{array}$ & $96 \%$ \\
\hline
\end{tabular}




\subsection{Identificação de Palavras Frequentes}

Foram identificadas as palavras mais frequentes para o grupo de comentários positivos (relacionados com a votação sim) e para o grupo de comentários negativos (relacionados com a votação não) dos projetos constantes da Tabela 1.

Essas palavras foram organizadas em Nuvens de Palavras. Essa nuvem uma representação visual que permite obter uma visão geral de um grupo de textos dando relevância as palavras que ocorrem com mais frequência. Um dos coautores deste artigo identificou manualmente as palavras mais relacionadas com transparência, segundo o grafo de transparência (ER-PUC Rio, 2013), nas duas nuvens de palavras geradas para cada grupo de comentários (Figura. 1. e Figura. 2.) O resultado é mostrado na Tabela 2.

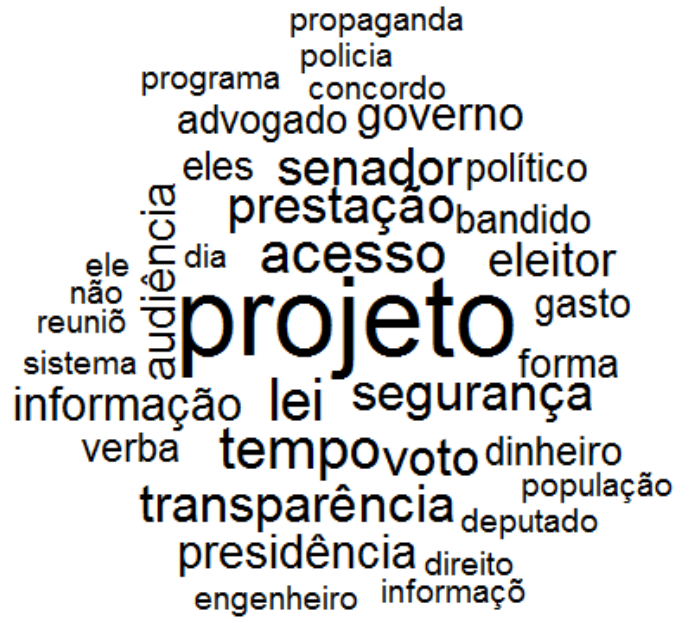

Figura. 1. Palavras mais frequentes em comentários de votação negativa

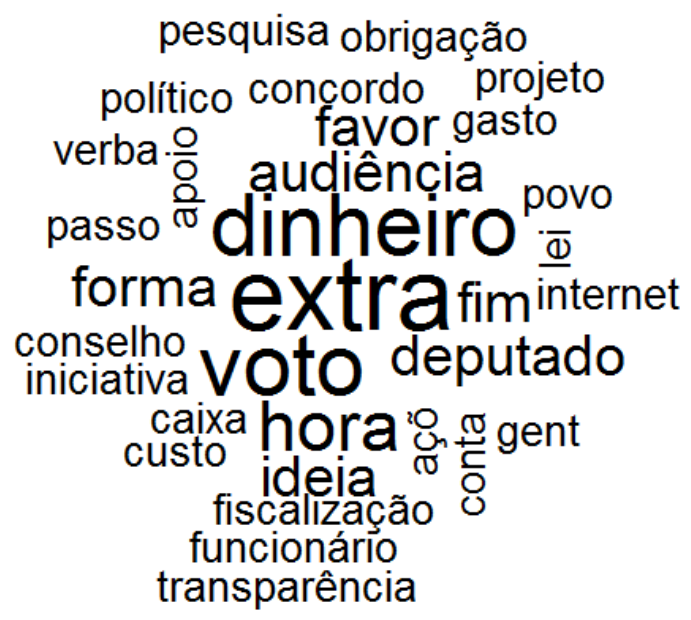

Figura. 2. Palavras mais frequentes em comentários de votação positiva

Tabela 2. Palavras frequentes relacionadas a Transparência.

\begin{tabular}{|l|l|l|l|l|l|l|}
\hline Comentários (Não) & acesso & prestação & transparência & audiência & informação & informações \\
\hline Comentários (Sim) & audiência & conta & fiscalização & internet & obrigação & transparência \\
\hline
\end{tabular}

\subsection{Busca de Indícios de Qualidade}

Palavras correlacionadas indicam o grau em que um ou mais atributos de um mesmo grupo de elementos possuem ao aparecer juntos. Assim, se duas palavras sempre aparecem juntas o grau é 1.0 .

Primero, se usou cada palavra da (Tabela 2) para calcular uma lista de suas palavras correlacionadas, colocando como limite inferior um grau de 0.60 de correlação. Segundo, em cada lista de palavras correlacionadas, um dos autores desse artigo identificou aquelas que estão relacionadas a transparência, usando seu conhecimento prévio sobre o tema e o grafo de transparência (ER-PUC Rio, 2013). Terceiro, foi gerada uma planilha que mostra a correlação entre as palavras (Tabela 3 ) e (Tabela 4). 
Tabela 3. Correlação de palavras relacionadas a transparência em comentários com voto negativo

\begin{tabular}{|c|c|c|c|c|c|c|}
\hline Indicios/ Qualidades & acesso & prestação & transparência & audiência & Informação & Informações \\
\hline acesso & & & & & 0.93 & 0.99 \\
\hline contas & & 0.98 & & 1.0 & & \\
\hline conta & & 0.98 & & 1.0 & & \\
\hline custo & & 0.98 & & & & \\
\hline demanda & & 0.98 & & & & \\
\hline divulgação & & & & 0.67 & & \\
\hline divulgações & & 0.98 & & 1.0 & & \\
\hline explicar & & 0.98 & & & & \\
\hline exposto & & 0.98 & & & & \\
\hline gastar & & 0.98 & & & & \\
\hline gastos & & 0.98 & & & & \\
\hline informação & 0.93 & & & & & \\
\hline informações & 0.99 & & & & & \\
\hline lei & 0.93 & & & & 0.88 & \\
\hline obrigação & & 0.98 & & & & \\
\hline particular & 0.99 & & & & & 1.0 \\
\hline periodicidade & & 0.98 & & & & \\
\hline prestação & & & & 0.98 & & \\
\hline privada & & & & & 0.95 & 1.00 \\
\hline privacidade & & 0.98 & & & & \\
\hline projetos & & & 1.00 & & & \\
\hline processo & & & 0.94 & & & \\
\hline pública & 0.99 & 0.98 & & 1.0 & 0.95 & 1.00 \\
\hline público & 0.99 & & & 1.0 & 0.95 & 1.00 \\
\hline transparencia & & 0.98 & & & & \\
\hline transparência & & 0.63 & & 0.67 & & \\
\hline votar & & & 0.94 & & & \\
\hline
\end{tabular}

Tabela 4. Correlação de palavras relacionadas a transparência em comentários com voto positivo

\begin{tabular}{|c|c|c|c|c|c|c|}
\hline Indicios / Qualidades & audiência & conta & fiscalização & internet & obrigação & transparência \\
\hline aberto & & & 1,0 & & & \\
\hline acompanhar & & & & 0,65 & 0,65 & 0,67 \\
\hline agilizar & & & & 0,65 & 0,65 & \\
\hline audiências & & & & 0,65 & 0,65 & 0,67 \\
\hline classificada & & & 1,0 & & & \\
\hline cobrar & & & & 0,65 & 0,65 & \\
\hline conhecimento & & & & 0,65 & 0,65 & \\
\hline conta & & & & & & 0,67 \\
\hline corrupção & & & & 0,65 & 0,65 & 0,67 \\
\hline custos & & & & 0,65 & 0,65 & 0,67 \\
\hline democracia & & & & & & 0,67 \\
\hline disponibilizar & & & & 0,65 & 0,65 & \\
\hline divulgações & & & & & & 0,67 \\
\hline explicação & & & & 0,65 & 0,65 & \\
\hline explícitas & & & & 0,65 & 0,65 & \\
\hline fiscalização & & & & 0,65 & 0,65 & \\
\hline fiscalizar & & & & 0,65 & 0,65 & \\
\hline impresso & & & & & & 0,67 \\
\hline informação & & & & 0,65 & 0,65 & \\
\hline internet & & & & 0,65 & 0,65 & 0,67 \\
\hline liberdade & & & & 0,65 & 0,65 & \\
\hline mafia & & & 1,0 & & & \\
\hline obrigatoriedade & & & 1,0 & & & \\
\hline públicas & & & 1,0 & 0,65 & 0,65 & 0,67 \\
\hline público & & & & & & 0,67 \\
\hline transparente & & & 1,0 & & & \\
\hline transparência & & & 0,65 & 0,65 & 0,65 & 0,67 \\
\hline obrigar & & & 0,65 & & & 0,67 \\
\hline obrigação & & & & 1,0 & 1,0 & 0,67 \\
\hline verba & & & & & & 0,67 \\
\hline
\end{tabular}




\subsection{Extração de Textos Usando as Palavras de Qualidade}

Os comentários foram minerados de acordo com as palavras relacionadas a transparência identificadas em (Tabela 3) e (Tabela 4). A lista completa dos comentários minerados foram publicados em GitHub (https://git.io/v9wyJ [issues 1-13]) para análises qualitativas posteriores. A (Tabela 5) apresenta o resumo do resultado final da mineração, mostrando o total de comentários obtidos. Assume-se o que todos os comentários foram corretamente identificados e possuem qualidades de transparência. Um ponto de atenção é que os comentários dos votos indecisos não foram considerados neste trabalho.

Tabela 5. Projetos identificados utilizando as novas técnicas

\begin{tabular}{|c|c|c|c|c|}
\hline \multirow{2}{*}{ Projeto de lei } & \multicolumn{2}{|c|}{ Comentários com voto sim } & \multicolumn{2}{|c|}{ Comentários com voto não } \\
\hline & Total & Minerados & Total & Minerados \\
\hline $\begin{array}{l}\text { Obrigará todos os senadores, deputados e vereadores a realizar } \\
\text { audiências públicas mensal com o objetivo de prestar informações } \\
\text { sobre sua atuacão parlamentar. }\end{array}$ & 39 & 21 & 14 & 14 \\
\hline $\begin{array}{l}\text { Obrigará a OAB e os outros conselhos profissionais a se } \\
\text { submeterem às regras da Lei de Acesso à Informação. }\end{array}$ & 18 & 7 & 6 & 4 \\
\hline $\begin{array}{l}\text { Tornará obrigatória a divulgação, na internet, da folha de } \\
\text { pagamento dos funcionários da Administração Pública Direta e } \\
\text { Indireta, incluindo adicionais, auxílios e gratificações. }\end{array}$ & 11 & 5 & 7 & 2 \\
\hline $\begin{array}{l}\text { Obrigará as universidades públicas e as unidades de pesquisa a } \\
\text { criarem arquivos online, de acesso livre, para guardar toda a } \\
\text { produção cientifica dos estudantes, professores, pesquisadores e } \\
\text { colaboradores. }\end{array}$ & 9 & 1 & 4 & 1 \\
\hline $\begin{array}{l}\text { Modificará o sistema de arquivamento dos votos em urnas } \\
\text { eletrônicas e os mecanismos de transparência dos votos. }\end{array}$ & 4 & 2 & 14 & 7 \\
\hline $\begin{array}{l}\text { Instituirá o programa de Unidades de Polícia Pacificadora (UPP's) } \\
\text { em todo território nacional. }\end{array}$ & 4 & 1 & 20 & 0 \\
\hline $\begin{array}{l}\text { Obrigará as empresas estatais federais a divulgarem, de } 3 \text { em } 3 \\
\text { meses, as despesas realizadas com publicidade e patrocínio no } \\
\text { Diário Oficial da União e em jornais de circulação nacional, para } \\
\text { aumentar a transparência dos gastos públicos. }\end{array}$ & 2 & 1 & 1 & 0 \\
\hline $\begin{array}{l}\text { Regulamentará a licitação e a contratação de serviços de } \\
\text { publicidade por parte da administração pública. }\end{array}$ & 1 & 1 & 1 & 1 \\
\hline Determinará obrigações para a realização de audiências públicas. & 0 & 0 & 1 & 0 \\
\hline $\begin{array}{l}\text { Excluirá da Presidência da República a Controladoria-Geral da } \\
\text { União, modificará o Conselho de Governo, passará as } \\
\text { competências do Departamento de Saúde Indigena, para o } \\
\text { Ministério da Saúde, entre outras mudanças no Poder Executivo. }\end{array}$ & 0 & 0 & 6 & 0 \\
\hline Total & 88 & 39 & 74 & 29 \\
\hline
\end{tabular}

\section{Necessidade por Transparência}

Para cada projeto considerado 10+ transparente, foram analisados os comentários filtrados para verificar as tendências:

O projeto PLC 1080-2011 Obrigará todos os senadores, deputados e vereadores a realizar audiências públicas mensal com o objetivo de prestar informações sobre sua atuação parlamentar. Nos comentários relacionados ao SIM verificamos uma tendência ao favor da participação da sociedade, um incentivo a prestação de contas e ao controle social. Os cidadãos acreditam que a prestação de contas e o acompanhamento dos gastos públicos é um passo para combater a corrupção. Já os comentários relacionados ao NÃO, mostram uma preocupação com os gastos públicos com essas audiências públicas. Os cidadãos se colocam a favor da transparência e divulgação de informações, apenas não concordam com a forma que está sendo proposta através das audiências que oneram os gastos públicos. 
Voto não. Tá faltando algo nesta [lei] do jeito que tá exposto, vai tornar mais moroso o [processo] legislativo, fora os gastos mensais com o evento prestação de [contas]. Prestação de [contas] é importante, mas precisa ser um meio mais dinâmico e menos oneroso.

Voto sim. [Transparência]! Devemos poder [acompanhar] ainda que pela [internet], o que cada parlamentar está fazendo. Essa é a melhor maneira de [fiscalização]. "... deverão [disponibilizar] em seus sites oficiais na [Internet] espaço destinado à consulta para todas as pessoas interessadas contendo informações sobre as [audiências] [públicas] realizadas..."

Figura. 3 Comentários no Projeto de Lei PLC-1080-2011

O projeto pls-193-2013, obrigará a Ordem dos Advogados do Brasil - OAB entre outros, se submeterem às regras da Lei de Acesso à Informação. Pode-se entender pelos comentários relacionados ao SIM, que os cidadãos concordam em que tais órgãos forneçam informações quando for solicitado, no entanto, os comentários relacionados ao NÃO também demandam transparência, mas restrita aos advogados.

Voto sim. Também deve ser estendido para as autarquias e Fundações
[Públicas]. Somente com [transparência] e [fiscalização] [popular]
diminuiremos o uso dessas instituições como caixa dois!
Voto não. Os conselhos profissionais não têm verba [pública] envolvida então
a lei de [acesso] à [informação] não se aplica se aplica apenas aos
profissionais de cada área registrados, estes sim podem solicitar [acesso] à
[informações], o [público] em geral não tem porque ter [acesso] às
[informações], porque um administrador ou um engenheiro precisa saber das
contas da OAB? se quem contribui são os advogados? Os Advogados sim precisam
ter [acesso] a [informações] da OAB, engenheiros do CREA e assim por diante.

Figura. 4 Comentários no Projeto de Lei pls-193-2013

O projeto de lei PLS-3497-2015 Tornará obrigatória a divulgação, na internet, da folha de pagamento dos funcionários da Administração Pública Direta e Indireta, incluindo adicionais, auxílios e gratificações) propõe a divulgação da folha de pagamento na internet. Os comentários relacionados ao SIM são relacionados a favor da transparência, divulgação dos dados, como também demandam um maior acompanhamento por parte da população do uso do dinheiro público. Os comentários relacionados ao NÃO expressam uma preocupação sobre a transparência e privacidade, que gera uma discussão de quais informações deveriam ser consideradas públicas e quais necessitam de um maior sigilo.

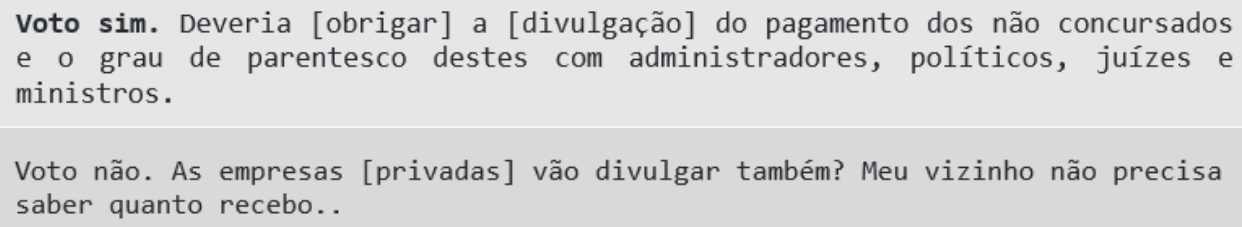

Figura. 5 Comentários no Projeto de Lei PLS 3497-2015 
O projeto PLS 387-2011 obrigará as universidades públicas e unidades de pesquisa a criarem arquivos online de acesso livre. O comentário a favor do projeto incentiva a acessibilidade aos trabalhos acadêmicos. Já o comentário contrário comenta sobre a questão de confidencialidade e entra novamente na discussão entre quais informações deveriam ser consideradas públicas e quais deveriam ser privadas.

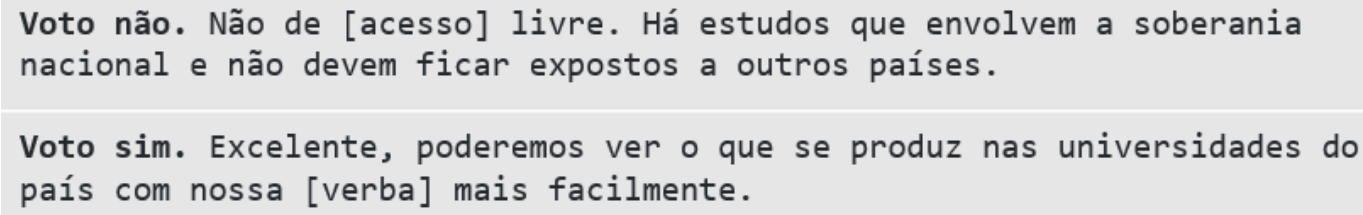

Figura. 6 Comentários no Projeto de Lei PLS-387-2011

O projeto PLS-68-2010, modificará o sistema de arquivamento dos votos em urnas eletrônicas e os mecanismos de transparência dos votos. Esse projeto de lei propõe o arquivamento dos votos nas urnas eletrônicas, ou seja, sem impressão de votos, mas com impressão e publicidade dos resultados por urna. Os comentários, tanto SIM como NÃO são contrários ao projeto, mas estão a favor da transparência. O cidadão acredita que o novo processo de arquivamento irá deixar o processo menos transparente possibilitando assim a corrupção e uma possível fraude eleitoral.

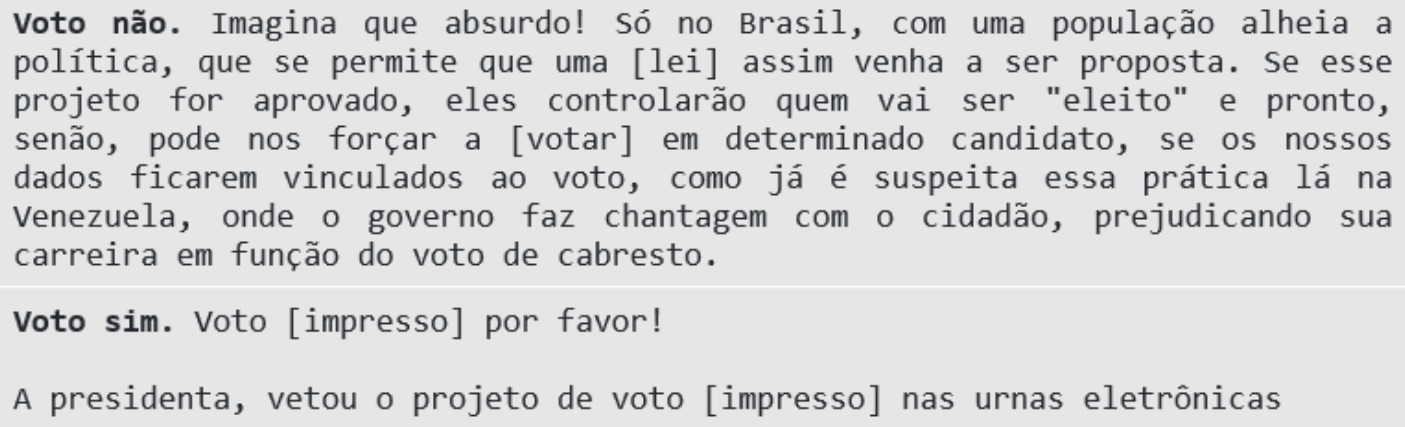

Figura. 7 Comentários no Projeto de Lei PLS-68-2015

O projeto PLC 370-2010 propõe a instituição das UPP's em territorial nacional, como já discutido no trabalho de 2016 (Engiel, Portugal, leite, 2016), esse projeto foi filtrado erroneamente, ele deveria ter sido removido da lista dos mais transparentes.

O projeto PLS-82-2009 obriga a divulgação das despesas realizadas com publicidade no Diário Oficial e em jornais. O comentário relacionado ao NÃO é a favor da divulgação das informações e assim da transparência, mas não concorda com a forma como é proposta, utilizando o diário oficial e os meios de comunicação o que gera custos para o governo. É proposta a utilização da internet que é grátis.

Voto sim. Concordo com o Eduardo que só na [Internet] é suficiente, MAS acho que é mais importante a [obrigação] da [divulgação] que o detalhe como é feita. 
O projeto PLC 3305-2008 é sobre a regulamentação da licitação e contratação de serviços de publicidade por parte da administração pública. O comentário relacionado ao SIM é a favor da fiscalização dos gastos públicos. O comentário relacionado ao NÃO é a favor da transparência apenas é contra o gasto público com publicidade.

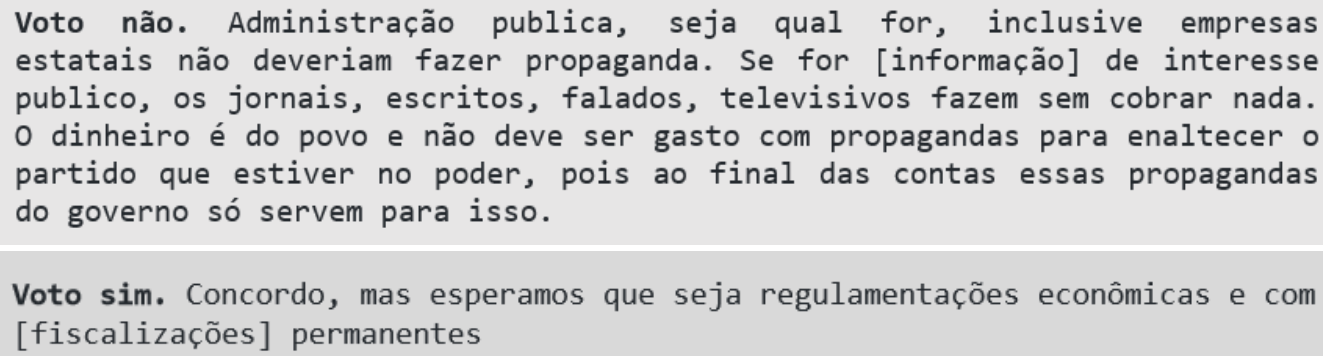

Figura. 9 Comentários no Projeto de Lei PLC-3305-2008

\subsection{Discussão}

Analisando os comentários verificamos uma tendência dos cidadãos a serem a favor da transparência. Podemos observar principalmente um incentivo a divulgação de informações, com objetivo de acompanhamento dos gastos públicos - uma maior participação da sociedade que através desses dados pode cobrar posturas do governo e assim contribuir para a diminuição da corrupção. Podemos observar que a maior parte dos comentários é relacionado ao nível 1 da transparência (Cappelli et al., 2010), divulgação da informação, acessibilidade. Os comentários contrários a transparência identificados são relacionados a privacidade, em uma discussão de quais dados devem ser divulgados e quais protegidos. Quando relacionados a gastos públicos a tendência dos comentários é solicitar a abertura, mas quando é citado dados privados, pesquisa, essa questão precisa ser mais analisada e discutida.

Uma característica saliente, é a população querendo ter uma participação maior, ficando mais engajada. A participação através do portal, votando os projetos e discutindo através dos comentários já é um passo para essa sociedade mais participativa, e com certeza a transparência ajuda atingir uma maior participação uma vez que dados e informações são fornecidas e a população pode acompanhar e cobrar por mudanças.

\section{Trabalhos relacionados}

Baia \& Braga (2013) verificaram a presença de atributos de transparência em modelos de requisitos que foram representadas utilizando o framework iStar. No entanto, como existem atributos que não puderam ser mapeados, para esses atributos foram buscados sinônimos que foram extraídos do WordNet ${ }^{1}$, um banco de dados lexical, ele agrupa palavras em inglês em grupos de sinônimos, prove definições curtas e exemplos de uso. Pode ser visto como uma combinação de dicionário e thesaurus. Essa estratégia é similar a nossa no sentido de que se procura mais palavras que possam ser uteis com palavraschave. Contudo, não foram reusadas tais palavras-chave para a nossa estratégia dado que elas estão em inglês.

\footnotetext{
${ }^{1} \mathrm{http}: / /$ wordnetweb.princeton.edu/perl/webwn
} 
Em relação a trabalhos de transparência utilizando portais web como fontes de informação, (Bittencourt et al., 2015) fizeram uso do catalogo de Transparência (ERPUC-Rio, 2013) para verificar se os portais de ensino superior oferecem transparência baseado em tarefas, uma delas por exemplo "obter endereço da secretaria de um curso específico". Esse trabalho se relaciona ao nosso no sentido de que o catalogo de transparência é útil como um meio para encontrar qualidades em textos, como também para ajudar na classificação de um artefato quanto ao seu nível de Transparência (Cappelli et al., 2010) .

Finalmente, (Paiva \& Revoredo, 2016) fazem o tratamento da grande quantidade de textos existentes em portais web como o Portal da Transparência do Governo Federal. O objetivo desse trabalho é melhorar o grau de transparência, dado que, a mera disponibilização de dados não é suficiente, sendo necessário encontrar formas de estruturar as informações de maneira que seja possível consolidá-las e agrupá-las, para assim serem melhor apresentadas.

\section{Conclusão}

Este trabalho verificou a demanda por transparência através de mineração de textos e análise qualitativa de comentários relacionados a projetos de lei. A mineração dos textos foi feita de forma automática utilizando ferramentas. Já a análise dos comentários minerados, foi realizada manualmente por um dos autores do trabalho. Os trabalhos anteriores focaram em filtrar os projetos de lei e fazer uma análise deles. Esse trabalho expandiu os estudos para os comentários sobre os projetos, analisando o que os cidadãos comentam sobre a transparência e quais são as suas estatísticas.

Foram minerados 67 comentários relacionados a transparência dos 138 comentários presentes para os 9 projetos de lei (já desconsiderando o projeto que foi minerado incorretamente), isso representa 48,5\% dos comentários. Analisando que existiam diversos comentários parabenizando o projeto, ou apenas concordando ou discordando de opiniões em muitos argumentos, podemos considerar esse resultado promissor, mostrando um interesse crescente da população pelo tema.

Sabemos que a amostragem de comentários do site, representa uma pequena parte da população, mas de qualquer forma a amostra examinada nos permite crer que população está engajada para uma sociedade mais transparente. Os cidadãos apoiam projetos relacionados a divulgação de informações, principalmente de gastos públicos e tem o objetivo e intuito de acompanhar esses dados, tornando uma sociedade mais participativa. A ideia de controle social sobre gastos públicos e a abertura de informações é um passo para que os cidadãos sejam mais participativos e assim possam demandar mudanças.

Um trabalho futuro é verificar manualmente os comentários e classificar os que são transparentes e comparar com os filtrados automaticamente para verificar a eficácia do processo de mineração e verificar possíveis melhorias. Outro trabalho futuro é realizar mineração de projetos utilizando outras fontes de palavras-chave que não seja o catálogo de transparência, uma possível fonte é o léxico de transparência de Engiel et al., 2015. 


\section{Referências}

Engiel, P., do Prado Leite, J. C. S., and Cappelli, C. Confirmando a Demanda por Transparência: Um Estudo Inicial sobre um Sistema de Avaliação de Projetos de Lei. II Workshop de Transparência em Sistemas, Londrina, Brasil. (2014)

Engiel, P., Pivatelli, J., Moura, P., Portugal, R., Cesar, J., \& do Prado Leite, S. (2015). Um processo colaborativo para a construção de léxicos: o caso da divulgação de transparência. In 18th Workshop on Requirements Engineering-WER.

Engiel, P., Portugal, R.L.Q., do Prado Leite, J. C. S. Descobrindo projetos de lei relacionados a transparência. IV Workshop de Transparência em Sistemas, Rio de Janeiro - RJ, Brasil. (2016)

Cappelli C, Leite J.C.S.P, Araujo R. M., . A Importância de um Modelo de Estágios para Avaliar Transparência. Revista do Tribunal de Contas do Município do Rio de Janeiro 45, 2010.

ER - PUC-Rio, 2013. Disponível em (http://transparencia.inf.pucrio.br/wiki/index.php/Catálogo Transparência). Acessado em 20/03/2017.

Baía, J. W., \& Braga, J. L. (2013). Uso de sinônimos na identificação de atributos de transparência. In 16th WER-Workshop em Engenharia de Requisitos (15th CibSECongresso Ibero-Americano em Engenharia de Software) (pp. 94-104).

Forte Neto, F. B., Vilain, P., \& de Macedo, F. F. (2015, May). A Customized Checklist for Analyzing Software Transparency in Websites. In Proceedings of the annual conference on Brazilian Symposium on Information Systems: Information Systems: A Computer Socio-Technical Perspective-Volume 1 (p. 47). Brazilian Computer Society.

Paiva, E., and Kate Revoredo. "Big Data e Transparência: Utilizando Funções de Mapreduce para incrementar a transparência dos Gastos Públicos." XII Simpósio Brasileiro de Sistemas de Informação (2016). 